\title{
Places Near and Far
}

Adventure is everywhere! Exploring Canada and other countries can be fun and educational, and books can take us on spectacular trips inward and outward. Through well-researched and authentic picture books, children can learn about different cultures as well as their own, with place appearing as a mirror with two sides - reflecting both ourselves and other people.

In this chapter we present some Canadian picture books published between 2017 and 2019 that take readers on amazing trips in all directions. Authors and illustrators can be commended for sharing their own lived perspectives as well as doing the research necessary to get these stories right! While many places are named specifically, others are unnamed, allowing readers to infer and imagine, comparing and contrasting various locations with their own lived habitat.

While the text in these picture books illuminates many aspects of here and there, employing a range of fiction and non-fiction genres, illustrations in this set of books also go into overdrive, presenting places and spaces in luminous detail with photographs, drawings, and gallery-quality paintings. Fasten your seatbelts for the journey ahead because these books really travel!

Where not otherwise indicated, the name of the author(s) appears first under each title, and the illustrator last.

\section{Nuptse \& Lhotse in the Land of the Midnight Sun Jocey Asnong}

This title is part of a series on two globetrotting cats. In this volume, they travel the Chilkoot Trail to the North Pole, encountering all four seasons, and entertaining themselves by panning for gold, riding a caribou across the tundra from boreal forest to Artic Ocean, and, with the help of an Inuit hunter, sailing among ice floes in the Northwest Passage. This book celebrates the uniqueness of Canada and the Arctic. For ages $5^{-10+}$. 


\section{Sharing Our Truths/Tapwe}

Henry Beaver, Mindy Willett with Eileen Beaver

and Tessa Macintosh

This detailed personal narrative about a family living in Fort Smith, North West Territories, celebrates the land and its people. With many photographs that depict Indigenous cultural practices and connections, the setting here is rich with teaching possibilities. For ages 4-adult.

\section{Goodnight, World \\ Andrea Lynn Beck}

A boy settles into his bed on a sailboat and wonders where other children sleep. Two pages at the end of the book provide facts about various types of homes around the globe including: domed houses in Syria; brick houses; houses with grass roofs; yurts made of wood and felt; houseboat homes; tree houses; apartments; mud homes; a house

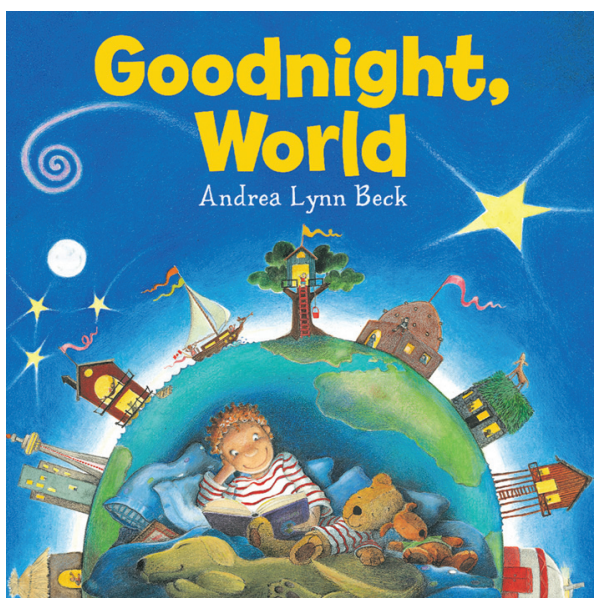
on stilts; and wooden houses. The illustrations throughout, with pencil crayon and paint on watercolour paper, are full of rich and colourful details that will engage young readers and offer further information. For ages 2-7.

\section{Summer North Coming}

Dorothy Bentley

and Jessica Bartram

This book celebrates summer and winter in the north. Its poetry is beautifully rhythmical with stunning vocabulary usage. Readers will make personal connections and learn new facts about Canadian settings and activities. Jessica Bartram's rich watercolour and gouache illustrations are an homage to the picturesque Canadian north. For ages $5^{-9+}$. 
A Halifax Time-Travelling Tune Jan L. Coates

and Marijke Simons

This lyrical story and its accompanying dreamy illustrations follow a young child back into 1950s Halifax, Nova Scotia, along with a magic song entity named "Tune." They dance through Point Pleasant Park, the Public Gardens,

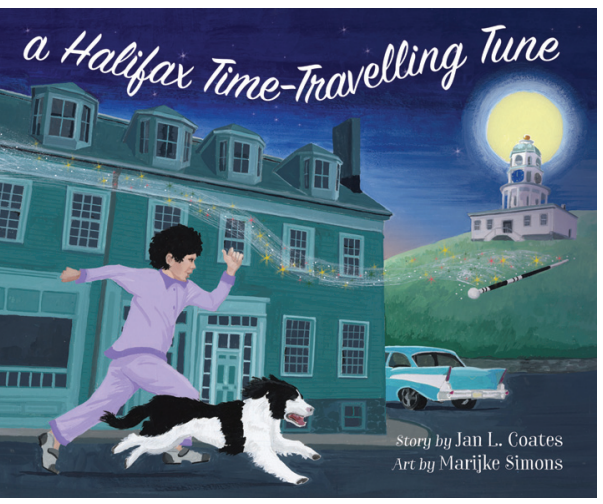
Citadel Hill, and other historic Halifax landmarks. Accompanied by two additional pages of vintage photos and related descriptions, this book is a celebration of Halifax's history. For ages 4-8.

\section{Capelin Weather \\ Lori Doody}

Kate experiences the gray, cold time at the beginning of summer on Newfoundland's shores. Her grandmother promises that the weather will be nicer after the capelin roll in. Kate watches for the little fish and sees all sorts of other things including icebergs, whales and kittiwakes... until the day when the capelin really do arrive. Lori Doody's folk art illustrations are playful and bright, offering a portrait of Newfoundland's natural beauty. For ages 4-8.

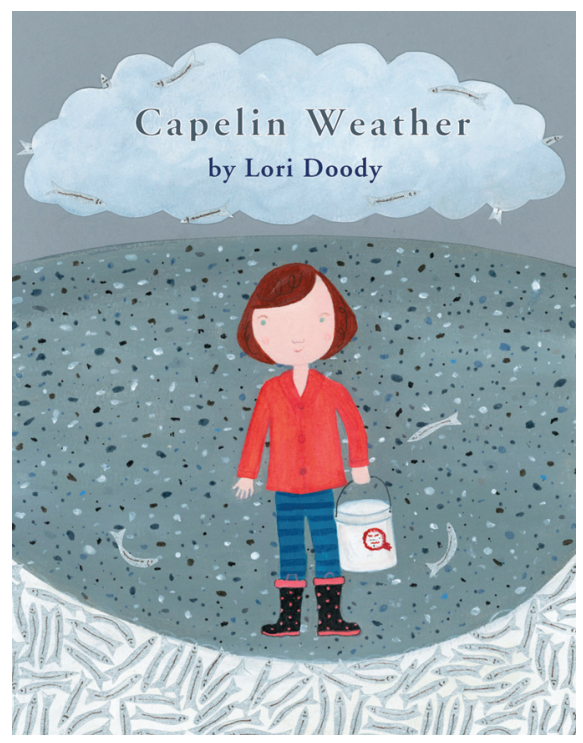




\section{The Puffin Problem}

Lori Doody

This story follows an imaginary influx of puffins into downtown St. John's, Newfoundland. The folk art images depict local businesses, and endnotes provide context for the story, explaining how puffins really do nest in St. John's each summer and often end up stranded on land, disoriented by artificial lights. Lori Doody's comical, spare, pencil and watercolour illustrations offer young viewers ample opportunities to locate distinctive puffins everywhere! For

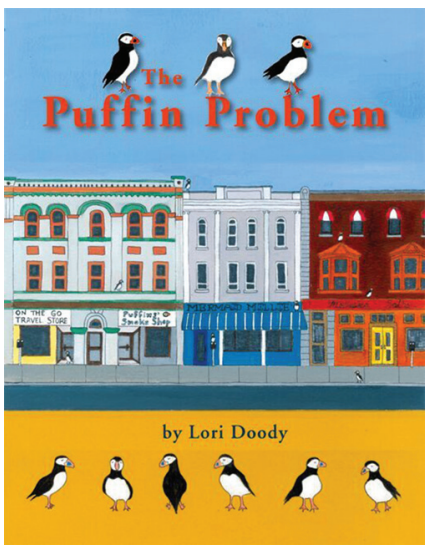
ages $3-8$.

\section{Milo and Georgie}

Bree Galbraith

and Josée Bisaillon

Milo and Georgie move with their mom to a new city, and Milo doesn't like it. To help his sister, he sends her out exploring on the end of a red string, so that when he tugs, she'll return. But one day he has to go and find her, and the trail leads readers through a detailed exploration of this city setting. Readers may be inspired to map out their own neighbourhoods in response to this look at one supportive community. Josée Bisaillon's watercolour, collage and digital illustrations are a visual feast. For ages $4-8$.

\section{My Winter City \\ James Gladstone \\ and Gary Clement}

An elegant, lyrical first-person text follows the experiences of a boy, his dad and their dog exploring winter in the city. Rich vocabulary and highly detailed watercolour illustrations fill the extra-large pages of this celebration of urban living. For ages $4-8$.

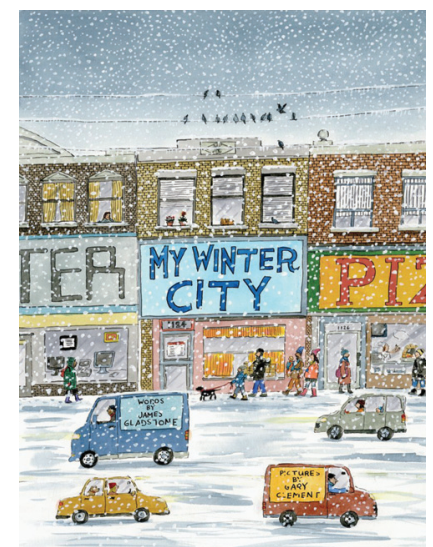




\section{Africville \\ Shauntay Grant \\ and Eva Campbell}

A young girl visits the former site of Africville, in Halifax, Nova Scotia, imagining what the community was like. Many details appear in textured illustrations created with oil and pastel on canvas. The author's note provides even more information about the vibrant Black community that thrived in the face of oppression for over 150

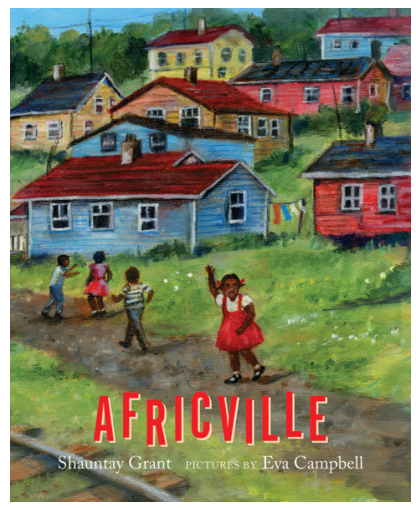
years. Africville was demolished by city officials in the 196os; in 2010, the City of Halifax delivered an official apology. This book offers the opportunity for discussions about injustice and racial discrimination. For ages $4-8+$.

\section{When the Moon Comes \\ Paul Harbridge \\ and Matt James}

This title nostalgically explores winter in a small community, culminating in an informal nighttime hockey game on a frozen beaver flood. Community traditions such as building a fire and clearing the ice are included in vivid, active paintings, rendered in acrylic paint and India ink, on oversize pages. For ages 4-8+.

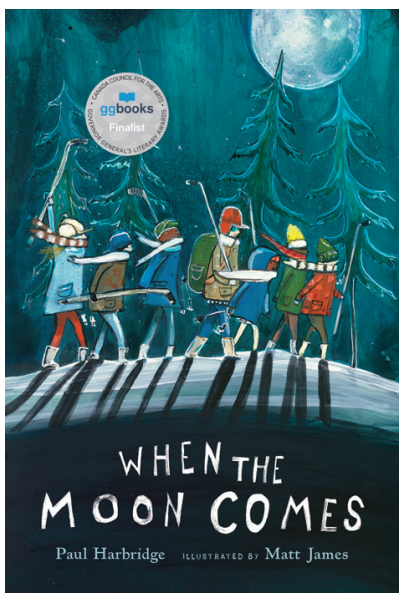

Up! How Families Around the World Carry Their Little Ones Susan Hughes

and Ashley Barron

From West Africa to Peru, from Egypt to Canada's Far North, from Korea to India, from Poland to China and Afghanistan, and other places called home, families carry their babies in many different ways. With simple words and cutpaper collage illustrations, readers are taken through a number of traditional customs. This is an original take on cultures around the world. For ages 2-7. 


\section{Here to There and Me to You \\ Cheryl Keely \\ and Celia Krampien}

This book spotlights well-known bridges around the world, identifying their different structures through simple text and drawings as well as more informative sidebars. These include: Canada's Hartland Bridge; California's Golden Gate; the London Bridge; Peru's Puente de Piedra; wildlife crossings in Banff National Park; the Whirlpool Rapids Bridge at Niagara Falls; the Three Countries Bridge at the borders of France, Germany and Switzerland; the Brooklyn Bridge; and, bridges closer to home: rope bridges, backbends, rainbows and hand-holding. For ages $5^{-9+}$.

\section{Sun Dog \\ Deborah Kerbel \\ and Suzanne Del Rizzo}

A puppy explores her Arctic home under the midnight sun before anyone else is awake. Suzanne Del Rizzo's striking illustrations in textured polymer clay and acrylic wash add important details to Juno's coming-of-age story. For ages 2-8.

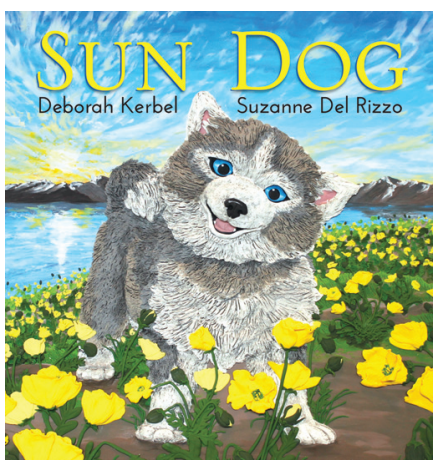

\section{Auntie Luce's Talking Paintings \\ Francie Latour \\ and Ken Daley}

Every year a young girl visits her aunt, a painter in Haiti, and this vividly illustrated story brims with the foods, sounds, and language that offer the protagonist a deeper understanding of Haitian history and culture including Black heroes important to the country. Luce Turnier, one of Haiti's celebrated artists, was the inspiration for this book, and Ken Daley's

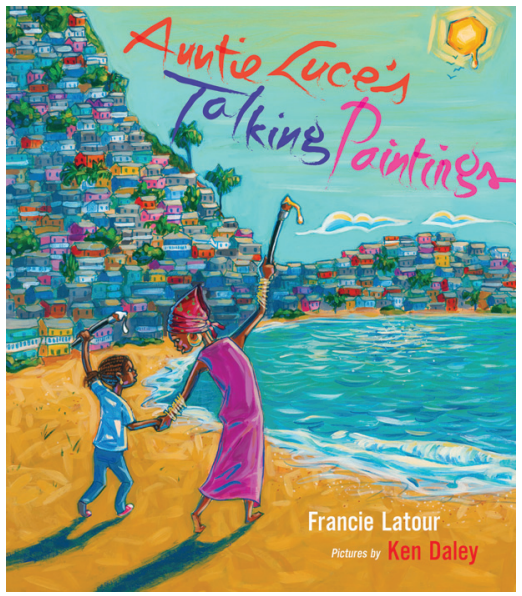
vibrantly painted landscapes, using acrylic on illustration board, evoke the tropical setting. While this title is about Haiti, it is also about identity and the ways we can learn to see ourselves. For ages $4-8$. 
Island in the Salish Sea

Sheryl McFarlane

and Leslie Redhead

Every day is a beach day and every day is different for the young narrator as she relates her adventures on Gran's island. Redhead's vivid watercolour paintings bring the plants and animals to life and offer panoramic seaside views. For ages $4-8$.

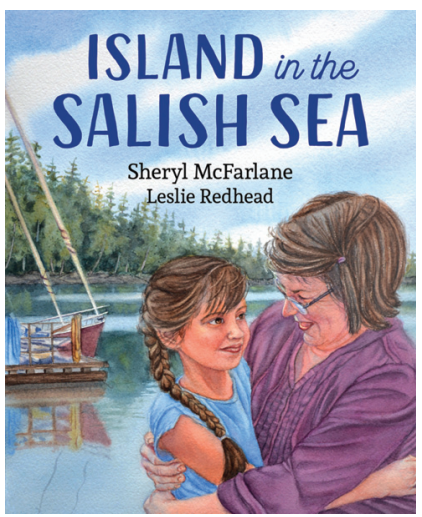

\section{The Gathering}

Theresa Meuse

and Art Stevens

Alex is attending her first Mi'kmaw spiritual gathering. Assisted by her older cousin, she meets Elders and learns about the Sacred Fire, drumming, tanning and moccasin decorating, weaving baskets, and canoe-making, followed by a feast. Most importantly, Alex finds her voice in the talking circle. This is an inclusive story that celebrates

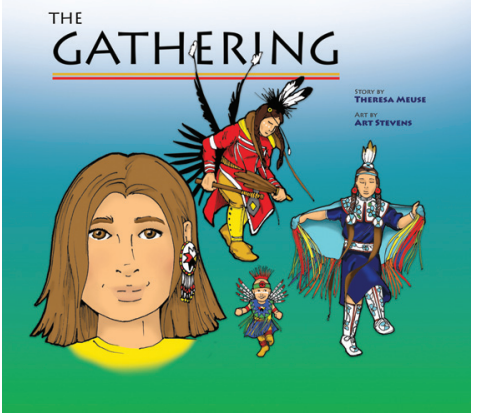
Mi'kmaw culture and kinship. For ages $5-8$.

\section{Am Canada}

\section{Heather Patterson}

and ${ }_{13}$ Canadian illustrators

With a simple text that identifies activities and landscapes common to living in Canada, this title has multiple illustrators who also include statements about what Canada means to them. Artists include: Cale Atkinson, Eva Campbell, Geneviève Côté, Danielle Daniel, Marie-Louise Gay, Doretta Groenendyk, Jon Klassen, Qin Leng, Irene

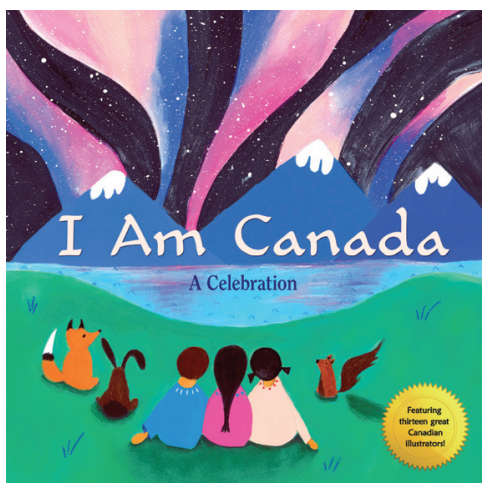
Luxbacher, Ruth Ohi, Barbara Reid, Ashley Spires, and Jeremy Tankard. This book will inspire great conversations among children and adults about being Canadian. For ages $3-7$. 


\section{Birthdays Around the World \\ Margriet Ruurs \\ and Ashley Barron}

The information in this book, in text and paper collage illustrations, is based on how real people from 14 countries around the world celebrate their birthdays. The countries included are: Australia, Belgium, Cambodia, Canada, Ghana, India, Jamaica, Japan, Latvia, Lesotho, Peru, Russia, the United States, and Vietnam. For ages $4-8$.

\section{She Dreams of Sable Island: A Paper Doll Book}

Briana Corr Scott

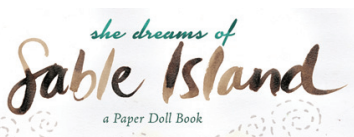

Scott is a celebrated artist whose paintings and poems are inspired by the natural world. Here she renders the story of a little girl who goes to Sable Island, Nova Scotia, in her sleep. After the main text unfolds in gentle rhyme, there is an informational section on the national park, followed by an illustrated double-page spread that describes local flora and fauna including a spotlight on the famous wild horses. Paper

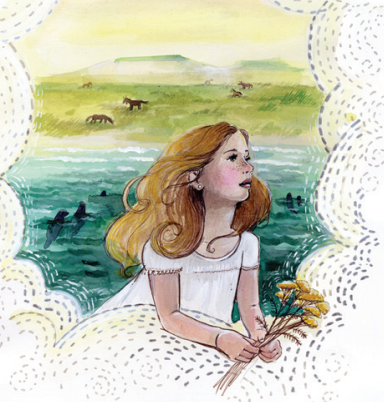

Briana Cars Seats doll cut-outs are included to engage young readers in retelling the story. This book is an evocative blend of fact and narrative non-fiction along with a hint of fiction, all set on Sable Island. For ages 3-9.

\section{Ten Cents a Pound}

Nhung N. Tran-Davies

and Josée Bisaillon

A young girl is torn by her desire to stay home in her isolated village and her dream to go to school on the other side of the mountains. Her mother is determined that her child will have a life beyond the coffee fields. Bisaillon's mixedmedia art work revels in earth tones, accented by the striking red coffee beans that sell for ten cents a pound. Tran-Davies' lyrical prose will catalyse discussions about poverty and education. For ages $5^{-8 \text {. }}$ 


\section{A West Coast Summer \\ Caroline Woodward \\ and Carol Evans}

This book brings together a collection of fine art images from watercolourist Carol Evans with rhyming text by author Caroline Woodward, who writes and works as a lighthouse keeper on Lennard Island, British Columbia. A title that definitely evokes the seaside, readers will happily explore the gorgeous images for details in the absence of a traditional storyline. For ages 3-8.

\section{The Promise}

Pnina Bat Zvi, Margie Wolfe

and Isabelle Cardinal

Auschwitz concentration camp is the historical setting for the saga of two sisters who eventually survived to tell this story to their daughters - the authors of this book. This title renders the inhumanity of war through its poignant story and haunting illustrations, but also the possibility of hope for humanity even in the darkest times. Isabelle Cardinal's haunting mixed-media illustrations use digital collage to combine photographs and sketches. For ages 7-12+.

\section{Bibliography}

*In the spirit of the recommendations of the Truth and Reconciliation Commission, an asterisk appears beside works created by Indigenous writers or artists.

*Asnong, Jocey (2019). Nuptse \& Lhotse in the Land of the Midnight Sun. Calgary, AB: Rocky Mountain Books.

*Beaver, Henry \& Willett, Mindy, with Eileen Beaver (illustrated by Tessa Macintosh) (2019). Sharing our Truths. Markham, ON: Fifth House.

Beck, Andrea Lynn (2019). Goodnight, World. Toronto, ON: Scholastic Canada.

Bentley, Dorothy (illustrated by Jessica Bartram) (2019). Summer North Coming. Markham, ON: Fitzhenry \& Whiteside.

Coates, Jan (illustrated by Marijke Simons) (2018). A Halifax Time-Travelling Tune. Halifax, NS: Nimbus Publishing.

Doody, Lori (2017). Capelin Weather. Tors Cove, NL: Running the Goat/Books \& Broadsides.

Doody, Lori (2017). The Puffin Problem. Tors Cove, NL: Running the Goat/Books \& Broadsides. 
Galbraith, Bree (illustrated by Josée Bisaillon) (2017). Milo and Georgie. Toronto, ON: Owlkids Books.

Gladstone, James (illustrated by Gary Clement) (2019). My Winter City. Toronto, ON: Groundwood Books/House of Anansi Press.

Grant, Shauntay (illustrated by Eva Campbell) (2018). Africville. Toronto, ON: Groundwood Books/House of Anansi Press.

Harbridge, Paul (illustrated by Matt James) (2017). When the Moon Comes. Toronto, ON: Tundra Books/Penguin Random House.

Hughes, Susan (illustrated by Ashley Barron) (2017). Up! How Families Around the World Carry Their Little Ones. Toronto, ON: Owlkids Books.

Keely, Cheryl (illustrated by Celia Krampien) (2017). Here to There and Me to You. Collingwood, ON: Sleeping Bear Press.

Kerbel, Deborah (illustrated by Suzanne Del Rizzo) (2018). Sun Dog. Toronto, ON: Pajama Press.

Latour, Francie (illustrated by Ken Daley) (2018). Auntie Luce's Talking Paintings. Toronto, ON: Groundwood Books/House of Anansi Press.

McFarlane, Sheryl (illustrated by Leslie Redhead) (2018). Island in the Salish Sea. Victoria, BC: Orca Book Publishers.

*Meuse, Theresa (illustrated by Art Stevens) (2018). The Gathering. Halifax, NS: Nimbus Publishing.

Patterson, Heather (illustrated by 13 Canadian artists) (2017). I Am Canada. Toronto, ON: North Winds Press/Scholastic Canada.

Ruurs, Margriet (illustrated by Ashley Barron) (2017). Birthdays Around the World. Toronto, ON: Kids Can Press.

Scott, Briana Corr (2019). She Dreams of Sable Island: A Paper Doll Book. Halifax, NS: Nimbus Publishing.

Tran-Davies, Nhung N. (illustrated by Joseé Bisaillon) (2018). Ten Cents a Pound. Toronto, ON: Second Story Press.

Woodward, Caroline (illustrated by Carol Evans) (2018). A West Coast Summer. Madeira Park, BC: Harbour Publishing.

Zvi, Pnina Bat \& Wolfe, Margie (illustrated by Isabelle Cardinal) (2018). The Promise. Toronto, ON: Second Story Press. 